\title{
EL RUIDO COMO ARTIFICIO
}

\section{Mattin Artiach Oraa}

Universidad del País Vasco / Euskal Herriko Unibertsitatea. Dpto. Arte y Tecnología. Doctorando

\section{Resumen}

El ruido es un término muy difuso. Sin embargo, también ha sido una práctica musical dentro de una tradición específica. Lo que primero me atrajo del ruido fue la posibilidad de sobrepasar los límites de lo que era aceptable: en lo sonoro, en lo cultural, conceptualmente y socialmente. Pero el ruido no es siempre perturbador. Para que sea perturbador es necesario encontrarse negativamente con una serie de expectativas. Una vez comprendidos los tropos del ruido, su efecto negativo crítico deja de ser válido. En este punto, identificaré parte del potencial que el ruido -como práctica musical- contiene para producir alienación y extrañamiento. Para ello, quiero usar el ruido como artificio, de manera similar a la que el formalista ruso Viktor Shklovsky utilizó su concepto de ostranenie (extrañamiento o desfamiliarización) y, mediante esto, defenderé que el ruido necesita ser entendido tanto de manera histórica como contextualmente.

\section{Palabras clave: RUIDO; ALIENACIÓN; IMPROVISACIÓN; EXPERIENCIA; EXTRAÑA- MIENTO}

\section{NOISE AS A DEVICE}

\section{Abstract}

Noise is a very diffuse term. However, it has also been a musical practice within a specific tradition. What first attracted me to noise was the possibility for pushing the limits of what was acceptable: sonically, culturally, conceptually and socially. However, noise is not always disruptive. In order to be disruptive it needs to encounter negatively a set of expectations. Once the tropes of noise have been understood, then its critical negative effect is no longer valid. Here I will identify some of the potential that noise- as musical practice- has for producing alienation and estrangement. In order to do this I want to use noise as a device in a similar way that the Russian formalist Viktor Shklovsky used his concept of ostranenie (estrangement or defamiliarisation), and in so doing I will argue that noise needs to be understood both historically and contextually.

Keywords: NOISE; ALIENATION; IMPROVISATION; EXPERIENCE; ESTRANGEMENT.

Artiach Oraa, Mattin. 2015. "Noise as device". AusArt 3 (2): 69-82. D0I: 10.1387 /ausart. 15986

\section{AUSART}




\section{EL RUIDO COMO ARTIFICIO ${ }^{1}$}

"La finalidad del arte es dar una sensación del objeto como visión y no como reconocimiento; los procedimientos del arte son los de la singularización de los objetos, y que consiste en oscurecer la forma, en aumentar la dificultad y la duración de la percepción. El acto de la percepción es en arte un fin en sí y debe ser prolongado. El arte es un medio de experimentar el devenir del objeto: lo que ya está "realizado" no interesa para el arte".

(Shklovsky 1965, 12)

En la historia del ruido ha habido incidentes, escándalos, malentendidos, emociones e ideas erróneas. Aquí intentaré dirigirme hacia donde creo que yace realmente el potencial del ruido. El ruido es un término muy difuso. Sin embargo, también ha sido una práctica musical dentro de una tradición específica. Lo que primero me atrajo del ruido fue la posibilidad de sobrepasar los límites de lo que era aceptable: en lo sonoro, en lo cultural, conceptualmente y socialmente.

Pero el ruido no es siempre perturbador. Para que sea perturbador es necesario encontrarse negativamente con una serie de expectativas. Una vez comprendidos los tropos del ruido, su efecto negativo crítico deja de ser válido. En este punto, identificaré parte del potencial que el ruido -como práctica musicalcontiene para producir alienación y extrañamiento. Para ello, quiero usar el ruido como artificio, de manera similar a la que el formalista ruso Viktor Shklovsky utilizó su concepto de ostranenie (extrañamiento o desfamiliarización) y, mediante esto, defenderé que el ruido necesita ser entendido tanto de manera histórica como contextualmente.

Shklovsky formó parte de los formalistas rusos junto a figuras como Boris Eichenbaum, Roman Jakobson, y Yuri Tynianov. Los formalistas rusos se interesaron en diferenciar las obras de arte en tropos, mecanismos o artificios (priem). Para Shklovsky, esto se hacía para raspar la superficie de la realidad, así como para desfamiliarizar la percepción autómata. Como ya dijo, "La obra de arte es la suma de su técnicas". Por lo tanto, Shklovsky encuentra la danza estructural de los artificios literarios tan arbitrarios e impersonales como los movimientos de las piezas de ajedrez.

Para Shklovsky, el ostranenie es un artificio usado en la escritura para contrarrestar la aclimatación de la percepción y, con ello, producir una sensación de 
desfamiliarización. En su famoso ensayo de 1917 El arte como artificio (otras veces traducido como El arte como técnica), coge como ejemplo de ostranenie un extracto de Kholstomer de Tolstoi, donde el narrador es un caballo que se halla desconcertado ante la creencia de los humanos en el sistema de la propiedad y la falta de coherencia en relación con lo que dicen y con sus actos. El pasaje merece ser citado en toda su extensión (como hace Shklovsky): "En esa época, no era capaz de entender lo que significaba el que yo fuera propiedad de un hombre. Las palabras 'mi caballo', que se referían a mí, a un caballo vivo, me resultaban tan extrañas como las palabras: 'mi tierra', 'mi aire', 'mi agua'. Sin embargo, ejercieron una enorme influencia sobre mí. Sin cesar, pensaba en ellas: y sólo después de un largo trato con los seres humanos me expliqué, por fin, la significación que les atribuyen. Quieren decir lo siguiente: los hombres no gobiernan en la vida con hechos, sino con palabras. No les preocupa tanto la posibilidad de hacer o dejar de hacer algo, como la de hablar de distintos objetos, mediante palabras convencionales. Tales palabras que consideran muy importantes, son, sobre todo: mío o mía; tuyo o tuya. Las aplican a toda clase de cosas y de seres. Incluso a la tierra, a sus semejantes y a los caballos. Además, han convenido en que uno sólo puede decir mío a una cosa determinada. Y aquel que puede aplicar el término mío a un número mayor de cosas, según el juego convenido, se considera la persona más feliz. No sé por qué las cosas son de este modo; pero me consta que son así. Durante mucho tiempo, traté de explicarme esto, suponiendo que redundaba en algún provecho directo; pero resultó inexacto. Muchas personas de las que me llamaban su caballo ni me montaban siquiera; y, en cambio, lo hacían otros. No eran ellos los que me daban de comer, sino otros extraños. Tampoco eran ellos los que me hacían bien, sino los cocheros, los herreros y, por lo general, personas ajenas. Posteriormente, cuando hube ensanchado el círculo de mis observaciones, me convencí de que no sólo respecto de nosotros, los caballos, el concepto mío no tiene ningún otro fundamento que un bajo instinto animal, que los hombres llaman sentimiento o derecho de propiedad. El hombre dice: 'mi casa'; pero nunca vive en ella. Tan sólo se preocupa de construirla y de mantenerla. El comerciante dice: 'mi tienda', 'mi ropa', por ejemplo; pero no utiliza la ropa del mejor paño que vende en ella. Hay gentes que llaman a la tierra 'mi tierra', pero nunca la han visto y jamás la han recorrido. Hay hombres que llaman a algunas mujeres 'mi mujer', 'mi esposa', y sin embargo, estas viven con otros hombres.[...] Las gentes no buscan en la vida hacer lo que ellos consideran el bien, sino la manera de poder decir mío del mayor número posible de cosas" (Shklovsky 1965, 15).

Aquí se puede ver cómo el desplazamiento de la voz desde la perspectiva del caballo, nos hace ver la realidad de manera diferente, de una manera que 
rompe el encanto de la apariencia de la realidad para continuar describiendo una cruel realidad por aquellos que no pueden expresarse por sí mismos.

¿Puede el ruido producir también este "raspamiento de la superficie"? Históricamente, sí. Es lo que lleva haciendo el ruido: alterar el orden de las cosas, hacernos conscientes de que aquello que dimos por estable, aquello que dimos por sentado, contiene elementos que no podemos descifrar. De modo similar al ostranenie de Shklovsky, el ruido fuerza la percepción, pero no porque "incorpore la sensación de las cosas como se perciben" sino porque no sabemos cómo tratar con ello. Produce un desequilibrio entre el conocimiento y la sensación. No es sólo una cuestión de sensibilidad, es una cuestión de que no contamos con las categorías conceptuales para abordarlo. Inevitablemente, esto es sólo una cuestión de tiempo.

El ruido lleva la percepción al límite porque hay algo en ello que no podemos descifrar apropiadamente. Hay algo que va más allá de nuestra categorización conceptual. No está bien indexado todavía y no contamos con las herramientas adecuadas para abordarlo. O hay algo que está mal o realmente muestra nuestra ineptitud para afrontar la realidad. En este sentido, nos acerca (a nosotros y a nuestros sentidos) a la realidad y a nuestra imposibilidad de darle un significado a la realidad. Esto es por lo que el ruido, en algunos aspectos, es lo más abstracto y, a la vez, lo más concreto de las expresiones culturales. Por un lado, es abstracto porque fuerza constantemente la complejidad para llegar a otro nivel que todavía no se ha explorado. Y concreto debido a que su especificidad tiene que ver con el residuo no reconocido que salió a la superficie en una situación de envío-receptor específica.

Por lo tanto, ¿que significaría reclamar la posibilidad de usar el ruido como artificio? Significaría incorporar y apropiarse de su propia decodificación. Mientras Shklovsky quiere prolongar lo "artístico" del objeto lo máximo posible y, con ello, prolongar una experiencia estética, yo propongo que la decodificación del ruido podría ser una forma de socializar el modo en que funciona su extrañamiento. Inevitablemente, esto implicaría la desaparición de dicho extrañamiento, pero también nos permitiría comprender cómo funcionan nuestras capacidades cognitivas y sensoriales. Al hacer esto, los problemas conceptuales que plantea el ruido podrían traducirse en más técnicas o artificios.

¿Por qué no prolongar la experiencia estética? Porque ambos ("estética" y "experiencia") son términos problemáticos que no debieran darse por sentados, especialmente si tenemos en cuenta el tipo de comprensión de la subje- 
tividad que presupone históricamente (con un fuerte vínculo con la noción del individuo).

El filósofo Ray Brassier (2009) dio en el clavo respecto al potencial del ruido para que no quede subordinado a la "estética": "Soy muy receloso de la 'estética': el término está contaminado por nociones de la 'experiencia' que encuentro profundamente problemáticas. No tengo una filosofía del arte de la que merezca la pena hablarse. Esto no es desechar la relevancia del arte por la filosofía - todo lo contrario- sino simplemente mostrar mis reservas en torno al tipo de esteticismo filosófico que parece querer defender la 'experiencia estética' como un tipo nuevo de paradigma cognitivo, donde se superaría la 'ruptura' de lo moderno (post-cartesiano) entre el saber y el sentir. A este respecto, diría que no puede haber una 'estética del ruido' porque el ruido, como yo lo entiendo, implicaría la destitución de la estética, concretamente en su registro post-kantiano, transcendental. El ruido exacerba la ruptura entre el saber y el sentir, disgregando la experiencia, forzando la concepción frente a la sensación. Algunos filósofos recientes han mostrado un interés en experiencias carentes de sujeto; yo estoy más interesado en los sujetos sin experiencia. Otro nombre para esto sería 'nemocentrismo' (término acuñado por el neurofilósofo Thomas Metzinger): la objetivación de la experiencia generaría sujetos que comprendieran ser nadie y estar en ninguna parte. Esto arroja nueva luz sobre las posibilidades de una subjetividad 'comunista'”.

Más adelante, intentaré rebatir que el ruido a menudo pueda producir esta "ruptura entre el saber y el sentir" y, con ello, se acercará a Shklovsky (1965, 8-9) cuando dijo: "Estoy estudiando la no-libertad del escritor". Desde la perspectiva de este trabajo, lo mejor que puede hacer el ruido es cuestionar las limitaciones de lo que consideramos como libertad y cómo se relaciona con lo que entendemos como producción de la subjetividad.

\section{CRÍTICA A SHKOLVSKY: EL RUIDO COMO CORRECTIVO}

Jameson es su libro The Prison House of Language critica la noción de Shklovsky del ostranenie en tres áreas conectadas entre sí:

a. La noción de Shklovsky del ostranenie no es histórica.

b. Para que cobre sentido la teoría de Shklovsky, es necesario aislar el material con el que se está trabajando y, por tanto, no nos permite 
enterderlo como texto (en un sentido Bartheano). Ej.: No nos deja tener en cuenta el contexto.

c. Hay ambigüedad respecto a si ostranenie reside en la forma, en el contenido o en el perceptor.

Respecto a la primera crítica, Jameson cita a Brecht para poder actualizar una comprensión histórica de cómo entender y utilizar el efecto de extrañamiento: "El efecto de la habituación es hacernos creer en la eternidad del presente para que crezca en nosotros una poderosa sensación de que las cosas y eventos que vivimos son, de alguna manera, "naturales" o, lo que es lo mismo, permanentes. El objetivo del efecto de extrañamiento de Brecht es, por tanto, algo político en el sentido más meditado de la palabra; es como lo que Brecht insistió una y otra vez para que seas consciente de que los objetos e instituciones que creías que eran naturales, en realidad, eran sólo históricos: El resultado del cambio, que ellos mismos de aquí en adelante sean cambiables (el espíritu de Marx, la influencia de su 'Tesis sobre Feuerbach' es clara.)" (Jameson 1972, 58).

El ruido siempre se entiende histórica y contextualmente. Sólo hay una excepción de lo que siempre se ha considerado como ruido: la dentera (como el sonido de las uñas sobre una pizarra) ${ }^{2}$. O como lo expone Jacques Attali: "El ruido, entonces, no existe por sí mismo, sino sólo en relación con el sistema en el que está inscrito" (Attali 1985, 26-7). Con respecto a la individualización, el ruido siempre se halla en el marco, pero también en los márgenes del marco. De hecho, el ruido constantemente socava su propio marco. O como afirma Miguel Prado: "Donde interfiere el ruido es en la suposición de una autonomía cerrada o una independencia dentro de un sistema" ${ }^{3}$. Los ejemplos individuales ponen en cuestión su propio proceso de individualización, argumentando siempre que hay algo que falta. Si el efecto de extrañamiento todavía está teniendo lugar, si todavía se da algo de ruido, entonces significa que nuestra compresión conceptual no es del todo capaz de captar lo que está ocurriendo, lo que a su vez, significa que es difícil individualizar algo de manera precisa.

En la historia de la música occidental siempre se ha dejado el ruido al margen, pero siempre vuelve porque, en realidad, se encuentra en la esencia de la música occidental (ej., en el tono). En una reciente conferencia sobre el ruido donde se presentó por primera este texto, Ulrich Krieger explicó muy bien cómo los tonos que escuchamos contienen ruido ya que un tono matemáticamente perfecto sonaría extraño a nuestros oídos ${ }^{4}$. 
Finalmente, sobre la cuestión de si el extrañamiento se da en la forma, en el contenido o en el perceptor con respecto al ruido, Attali $(1999,26-7)$ responde desde la perspectiva de la Teoría de la Información: "El ruido es el término que se atribuye a una señal que interfiere en la recepción de un mensaje por parte del receptor, incluso en el caso de que la señal de interferencia tenga un sentido para el receptor".

\section{TENSIÓN}

Si no existe el silencio, entonces, ¿qué hay ahí? Hay información, pero dentro de esta información hay ruido, un ruido que todavía no definiremos como algo específico (Ej.: música). Dado que es muy difícil situar específicamente el ruido en el contexto del que estoy hablando, aquí me referiré al ruido en el sentido general al que Jacques Attali se refirió como "una señal que interfiere con la recepción de un mensaje por parte del receptor".

Esto me permitiría no centrarme necesariamente en el fenómeno del sonido, sino en el "material" general que puede interferir en el receptor cuando intenta decodificar un mensaje, lo cual sería un concierto en el contexto al que me refiero. En este sentido, esto incluiría elementos que no son fenómenos, como las expectativas y las proyecciones de la gente involucrada y el ambiente general que pueda generarse.

¿Cómo saber cuándo el ruido produce el efecto de extrañamiento? En situaciones de concierto, podemos percibir el efecto de extrañamiento cuando hay tensión en el ambiente. Esta tensión se produce debido a que hay una serie de expectativas que no se están cumpliendo. Al mismo tiempo, la gente proyecta lo que está ocurriendo pero sin tener unas referencias claras. Hay confusión y, a la vez, hay concentración.

Si hay tensión -ya que el ruido está produciendo este potencial crítico (ej., una reconsideración de lo que significa 'crítico')- es porque los mecanismos de seguridad que nos permiten "entenderlo" no están funcionando. Se dan diferentes lógicas. La gente piensa de manera diferente sobre lo que está ocurriendo, en el sentido de que no hay una unidad de pensamiento posible que pueda usarse para describir la situación. 
Esta tensión no permite una experiencia subjetiva completa, no puedes simplemente sumergirte en lo que percibes ya que se da una fricción entre la realidad que estamos viviendo y nuestra incapacidad para abordarla. Intentaré explicar esto a través de mi propia práctica. Acumulo años de experiencia haciendo ruido y música improvisada con un ordenador, pero llegó un momento en el que se hizo evidente que el ruido se había convertido en un género musical con tropos específicos que se estaban convirtiendo en una parodia de sí mismo (volumen alto, frecuencias agresivas, movimiento total o inmovilidad total...). Así que empecé a interesarme en un enfoque del ruido distinto, un enfoque que tuviera que ver con el silencio, pero unos silencios llenos de expectativas ya que uno no sabe lo que puede pasar después. Esto vino de un cambio en mi comprensión sobre la improvisación, no como un acto de interacción entre los músicos y sus instrumentos, sino como una interacción social colectiva que se da en un espacio dado sin posiciones neutrales (como la del espectador). Por lo tanto, asumiendo -tras el 4'33" de Cage- que no existe el silencio y que el público puede perfectamente producir sonidos, incorporé una perspectiva marxista en mi intento de comprender y exponer cómo se producen las relaciones sociales en un espacio dado.

La interacción social se da de forma sencilla si los músicos no usan instrumentos. Por el contrario, a través de gestos genéricos accesibles para todos -como el habla o moverse por el espacio- es posible generar reacciones sin precedentes tanto desde el público como desde los músicos. Ya no es una interacción anticipada de antemano por un músico o un director (como en el caso de Brecht), sino que se ponen sobre la mesa unos elementos para generar lo inesperado que, con un poco de suerte, produzca una tensión y un extrañamiento en todas las personas involucradas, incluidos los propios músicos.

La pre-condición para producir tensión tiene que ver con suspender el contrato consensuado entre el público y los músicos. Si se da esta tensión, no nos relacionamos con los demás bajo la forma del consenso porque los elementos necesarios para constituir un consenso han desaparecido. En este sentido, la situación se desencadena. Hace pensar a todo el mundo sin un rol prescrito del todo. $Y$ es en este proceso donde emerge una auto-conciencia colectiva. No sabemos cómo relacionarnos ni con uno mismo, ni con los demás. Esto fuerza a la gente a pensar las relaciones con los demás sin una prefiguración. Ya no se trata de la mala sociabilidad del consumidor ni del espectador emancipado. Simplemente implica una suspensión de los roles bien definidos, donde la gente experimenta y explora su propio condicionamiento o, dicho de otra manera, su ausencia de libertad. 
Tu papel como oyente no puede darse por sentado, lo cual socava la socialización capitalista: no estás simplemente consumiendo algo. Y sin embargo, eres parte de ello. A través de la participación forzada donde no se te consulta previamente, te recuerdan que no eres un individuo soberano, que no tienes opción de permanecer neutral, que no eres libre. Con dinero siempre puedes negociar tu situación en el capital. Cuanto más dinero tengas, más poder tendrás y más podrás elegir tu situación.

Marx quiere libertad para el individuo, pero sólo es posible dentro y a través de la comunidad. La condición de mi libertad es la condición para la libertad de todos. Ahora parece que mi libertad se ha comprado a expensas de otros. Mi habilidad para consumir se da a expensas de otros, para producir bienes bajo circunstancias terribles. La alienación sistemática no puede negarse sólo con una participación discursiva o haciendo ruido juntos. Vivimos bajo una explotación estructural y sistemática, lo que implica que no hay posibilidad para un tipo de negación inmediata en todo el conjunto de redes de mediaciones. No hay una negación inmediata de mediación como tal. La inmediatez falsa ha estado demasiado presente en el ruido y en la improvisación libre.

Tenemos que pensar sobre nuestras condiciones de la experiencia, pero no con un pensamiento indeterminado, sino con uno determinado. Debemos encontrar un punto específico en el que enfocarse, donde el ruido puede ser ese foco precisamente porque no lo controlamos y porque cuestiona nuestras condiciones de experiencia. ¿Qué estoy presenciando? ¿Cómo me comporto una vez suspendida la relación público-músico? ¿Cómo nos relacionamos una vez que ya noconsumimos pasivamente? Algunos reafirmarían su individualidad, reafirmándose a sí mismos. Yo rechazo esta posición, la rechazo por dar por sentada una noción del individuo fermentado bajo condiciones capitalistas.

Mucha gente podría intentar conciliar esta experiencia como una broma o un chiste restableciendo la normalidad, como si no pudieran tolerar el tener que pensar sobre lo que está sucediendo y por qué está sucediendo. En mi experiencia, cuando se produce tensión, puede ser en dos direcciones:

a. La gente se reafirma a sí misma, su conocimiento y autoridad, pretendiendo ser inteligentes haciendo un chiste o comportándose como si ya lo hubieran visto antes. Esta actitud mata la tensión.

b. La gente sigue la tensión y cuando ocurre, surge una cierta honestidad donde las contribuciones individuales se convierten en parte de una agencia colectiva racional que trata de dar un sentido a la situación, comprendiendo que hay un ruido indescifrable. 
Hay algunas técnicas que pueden ayudar a acelerar la tensión y el extrañamiento, como por ejemplo: "punzar el espacio" (colocar los muebles de manera no convencional), "samplers humanos" (samplear y repetir cosas que se hayan dicho en el espacio), "glitchear la voz" (fallos en el discurso)," realismo anti-social" (colapsar la impotencia de cambiar las convenciones sociales en el lugar de la actuación con la impotencia de cambiar la realidad en un sentido general), "socavar la situación" (romper estas convenciones sociales), "volverse frágil" (compartir profundas inseguridades y dudas), "atreverse juntos y juntas" (realizar esta socavación colectivamente).

Una vez conseguida esa tensión, a continuación intentamos medir su potencial crítico. El ruido puede ser transformativo precisamente porque te hace conectar con otros aspectos de la realidad que no son necesariamente sonidos. A través de ello, se pone en primer plano su especificidad histórica. Es en el proceso de socialización de este desciframiento donde puedo ver el potencial del ruido entendido como artificio.

\section{TRES NIVELES}

Hay tres niveles con los que podemos medir la conciencia que el ruido puede producir; conciencia, conciencia como y conciencia de los mecanismos que producen una conciencia. ${ }^{5}$

Conciencia: Esto sería el ruido entendido como una absoluta inmersión en el sonido del oyente, lo que podría implicar también un enfoque más fenomenológico del ruido. No es ninguna sorpresa que este enfoque que la gente reivindica, a menudo implique un énfasis muy individualista. Como, por ejemplo, en Francisco Lopez ${ }^{6}$ o en VOMIR. De hecho, con VOMIR podemos ver esta conexión entre el ruido como una autonomía absoluta y una política individualista en su Noise Wall Manifesto ": "Al individuo ya no le queda otra alternativa que rechazar frontalmente la vida contemporánea bajo la forma en que se ha promovido y adulado. El único comportamiento libre que queda reside en el ruido, una retirada y un rechazo a rendirse ante la manipulación, la socialización y el entretenimiento". Encuentro este enfoque de lo más problemático precisamente porque sería el más estetizado y porque implica una cierta agencia del individuo que, bajo estas condiciones, sería una reclamación muy cuestionable. 
Conciencia como: Aquí tendría que tomarse en consideración el contexto: tienes el mapa e identificas otras referencias. Ya te aleja de una total inmersión en el sonido. Me vienen a la cabeza un par de ejemplos:

a. 4'33" de Cage: Incluso si él hubiera querido abordar los sonidos sólo como sonidos en sí mismos, esta pieza hace cuestionarte sobre qué es la música y rompe con juicios de valores previos, el público necesita cuestionarse a sí mismo y a sus roles (¿Son productores de sonidos y/o perceptores?).

b. Junko y su voz extrema, que desencadena las situaciones imaginarias más perturbadoras $\mathrm{y}$, sin embargo, su forma de gritar es la más neutral sin ninguno de los clichés del ruido: agresión, con referencias a asesinos en serie o a campos de concentración o, simplemente, pura expresión como si fuera un acto de libertad. Yo diría que su trabajo produce esa ruptura entre el saber y la sensación ya que rompe cualquier reconciliación entre tus habilidades cognitivas para afrontarlo y el cómo te hace sentir.

Aquí podemos ver cómo el ruido ya no se relaciona sólo con el sonido, sino que toma en consideración otros aspectos que tienen que ver con el contexto, la recepción histórica del material y nuestra habilidad para afrontarlo.

Conciencia de los mecanismos que producen una conciencia: Este último nivel es el más transformativo puesto que te hace reconsiderar tu relación no sólo con el contexto, sino también con los mecanismos que posees para abordar este contexto. Esto, inevitablemente, no consistiría solamente en una experiencia estética, sino también en cuestionar qué es la experiencia y cómo se produce. Pero lo más importante: Cómo se produce la subjetividad. No sólo forzaría la concepción frente a la sensación (como en el caso de Junko), sino que también forzaría el proceso de objetivización en el que tendrías que mirarte desde un tercer punto de vista o perspectiva porque los medios para sentir y poder verte como un individuo se están socavando.

Por ejemplo, no se da del todo tu condición como público o como músico, con lo que puede haber un elemento donde cambien las posiciones a condiciones que todavía no se han descrito. Esto resistiría el fetichismo de la singularidad de una única experiencia. 


\section{LA SOCIALIZACIÓN DEL RUIDO COMO ARTIFICIO}

¿Por qué sería importante intentar socializar el efecto de alejamiento que el ruido ejerce sobre nosotros? Debemos tener en cuenta que tanto las estrategias formalistas como el ruido se están recuperando con unos propósitos despreciables. Anthony lles comenta en su texto (2015) cómo se usan algunas estrategias formalistas en Gran Bretaña: "De manera inquietante, hemos descubierto recientemente en la reforma de la educación primaria y superior en el Reino Unido - una 'estética formal de la psicología del comportamiento' - una reformulación problemática y un uso de las técnicas formalistas con el fin de producir un sujeto autómata que se ajuste a las necesidades instrumentales de la crisis del capitalismo". Esto se hace para que los estudiantes desarrollen una mejor adquisición de la información y 'estimule' el 'desarrollo' cognitivo del individuo estudiante (lles 2015, 7273)".

Respecto al ruido, podemos ver cómo se lleva usando en los campos de bataIla, en la tortura y en las ciudades, con el fin de disolver manifestaciones. James Parker recientemente realizó una gran charla, Towards a Jurisprudence of Sonic Warfare ${ }^{8}$, en la que destaca cómo el uso de cañones sónicos como el LRAD 500X-RE -el modelo que se ha usado en las manifestaciones de Ferguson, pero también en Gaza y otros lugares- plantea unas tretas jurídicas muy útiles para los gobiernos ya que no se puede probar su culpabilidad por el daño infringido: No hay un impacto físico que se haya probado como causante del daño (podría haber sido música a un volumen alto en los auriculares). U otra forma perversa de recuperación, como lo que comenta Parker sobre el grupo Skinny Puppy, que está intentando que el gobierno de EEUU deje de usar su música para la práctica de la tortura.

Estas, por supuesto, son las más perversas formas del potencial crítico negativo del ruido. Sin embargo, lo que aquí se discute es que haya un potencial crítico negativo del ruido que pueda impulsar nuestro pensamiento y nuestra percepción que apunte donde no sabemos lo que significa "nuestro". Este enfoque sobre el ruido iría en contra de la absolutización de la experiencia como una reserva para la agencia. Hacer de esto una socialización de los efectos alienantes del ruido por medio de la comprensión racional, sería algo necesario para poder entender cómo funciona. Usar el ruido como artificio implicaría usar su potencial alienante, producir experiencias jodidas que haría cuestionarnos a nosotros mismos como sujetos. Si te reafirma a ti mismo como sujeto (lo pillo o me gusta), entonces no sería ruido como artificio, sino 
ruido como gusto, el cual no podría expandirse mucho más allá del yo que tiene experiencias. Lo importante es identificar si el ruido posee su efecto de extrañamiento y si deja de poseer este efecto alienante, necesitamos recargar su potencial negativo crítico constantemente, para que no se convierta en una parodia de sí mismo en el peor de los sentidos.

\section{Referencias}

Attali, Jacques. (1977) 1999. Noise: The Political Economy of Music, translation by Brian Massum Minneapolis: University of Minnesota

Brassier, Ray \& Bram leven. 2009 "Against an Aesthetics of Noise". nY, website en tijdschrift voor literatuur, kritiek \& amusement voorheen. Acceso 20 abril 2015. http://www.nyweb.be/ transitzone/againstaestheticsnoise.html

Iles, Anthony. 2015. "Studying Unfreedom: Viktor Shklovsky's Critique of the Political Economy of Art". Rab-Rab Journal for political and formal inquirities in Art 2(2). Helsinki: Rabrab

Jameson, Frederic. 1972. The Prison House of Language. Princeton, NJ: Princeton University

Shklovsky, Viktor. 1965. "Art as Technique". En Russian Formalist Criticism: four essays, translated and with an introduction by Lee T. Lemon and Marion J. Reis, 3-140. Lincoln: University of Nebrask

Vomir [Romain Perrot]. 2008. Manifeste du Mur Bruitiste [Proclamation of the Bruitist Wall]. Acceso 17 mayo 2015. http://www.decimationsociale.com/app/download/5795218093/ Manifeste+du+Mur+Bruitiste.pdf

Notas

${ }^{1}$ Una versión anterior de este trabajo se presentó en la conferencia Noise and the Possibility of the Future organizada por Warren Neidich, Goethe Institute, Los Angeles, 7 de marzo de 2015. Agradecimientos a Warren Neidich, Ray Brassier, Anthony lles y Sezgin Boynik.

${ }^{2}$ En una entrevista para Sonic Acts, Hillel Schwartz habla de esto aproximadamente a partir de 2'20". Accedido el 17 de mayo de 2015. https://vimeo.com/113593758

${ }^{3}$ Miguel Prado, "Schelling's positive account on noise: On the problem of Entropy, Negentropy and Anti-Entropy". Trabajo no publicado, 2015.

${ }^{4}$ Ulrich Krieger, "Noise - A Definition" (charla desarrollada durante la conferencia Noise and the Possibility of the Future organizada por Warren Neidich, Goethe Institute, Los Angeles, 6-7 de marzo de 2015).

${ }^{5}$ Este compresión triádica del potencial del ruido proviene de una conversación con Ray Brassier.

${ }^{6}$ Como puede leerse en su biografía sobre lo que intenta producir: "Una escucha transcendental, libre de los imperativos del conocimiento y abierta a la expansión sensorial y espiritual". Accedido el 13 de mayo de 2015. http://www.franciscolopez.net/ 
${ }^{7}$ Manifiesto HNW de VOMIR. Accedido el 17 de mayo de 2015. http://www.decimationsociale. com/app/download/5795218093/Manifeste+du+Mur+Bruitiste.pdf

${ }^{8}$ Esta charla se llevó a cabo en el Liquid Architecture Festival, Melburne, 11 de septiembre de 2014. Agradecimientos a James Parker por enviarme su material y a Danni Zuvela y Joel Stern por avisarme.

Anti-Copyright

Traducción al castellano de Iñigo Eguillor

(Artículo recibido 28-11-15; aceptado 09-12-15) 